\title{
Horizontal Urban Expansion And Livelihood Adjustment Problem Among Ex-Farmers In The Kebeles Surrounding Jimma Town: The Case Of Derba Kebele
}

\author{
Tamirat Mengistu, Lecturer \\ Jimma University,Ethiopia
}

doi: 10.19044/esj.2016.v12n14p308 URL:http://dx.doi.org/10.19044/esj.2016.v12n14p308

\begin{abstract}
This study is aimed at examining the livelihood strategy, benefit packages offered, adjustment problems and the coping strategies of exfarmers in the re-located neighbourhood of Derba kebele in Jimma town. To this end, the research site was purposively selected and in-depth interview with key informants; one focus group discussions and observation were used to collect the data required for the study. The study result showed that the livelihood of ex-peri-urban community has been jeopardized following the relocation to Hirmata Mercato kebele. This is because of the changes in the contexts that surrounds rural area and urban area. Since urban contexts are distinct from the rural ones and the households were not ready to be familiarized with the situation,and also the nature of follow-up and support given at post displacement time was less, majority of them lead a precarious living condition. As a result, majority of the households are not contented with the livelihood they are leading in the Hirmata Mercato Kebele.
\end{abstract}

Keywords: Livelihood, displacement, coping mechanism, compensation, poor, urban sprawl, horizontal urban expansion, Jimma,Derba

\section{Introduction: Background of the Study}

Urbanization and urban growth are considered as a modern way of life which manifests economic growth and development in many countries. That means the level of urbanization and socio-economic status of the inhabitants is correlated in many countries. Urbanization in Ethiopia faces a number of problems due to sometimes unplanned settlement and slums which characterize some of the larger cities of the country. In Ethiopia, Addis Ababa has this character due to the historical background of its establishment.i.e.lack of the proper planning at the initial point. The settlement pattern practiced in the city was scrambling the conquered land to 
the feudal chiefs, and garrison of the king following the military hierarchy. This traditional feudal settlement of land holding was practiced over the extended forest and agricultural land around the outskirts of Addis Ababa. The chiefs, Dejazmaches and Rases, were given large forest and farmland around the royal area and they in turn divided these into plots to their immediate subordinates to settle in the feudal manner and built their own houses on their holdings at the fringes of Addis Ababa. Thus, under this circumstance, the hinterlands of Addis Ababa were occupied in the past by evicting the lands of peasants (Feyera, 2005).

In Addis Ababa, the reclassification of rural areas in the periphery to urban settlement increased urban physical growth. After 1974, the Derg nationalized urban land and extra houses and transferred them to a public property. According to Feyera, the administration that the Derg introduced had brought significant change on the utilization of urban land. No land was provided legally to individuals for any kind of construction, for the improvement of the city or residence. Moreover, the inner city became densely populated with no improvement in house provision to meet the increasing demand. Latter, squatter settlement and illegal land trade intensified in the peripheries leading to the extension of Addis Ababa to the periphery. Due to this fact, the livelihood base of farmers increasingly threatened severely by the time. And hence, the farmers were forced to relocate from their place of residence by the urban physical growth (Bekure 1999: 16, Solomon 1985: 39 cited in Feyera, 2005:2-5).

Because of the problem of lack of legal transfer of land to individuals people in the inner city faced the shortage of residences in Addis Ababa during the Derg regime. As a result, the Derg administration tried to implement self-help housing cooperative system to fulfill the rising demand for residential use. Hence, the city outskirts occupied by farmers were allotted to new settlement construction by government. This new form of urban land consumption intensified dislocation of farmers from their farmland, which was a kind of eviction without compensation. As pointed out by Birke (1997) in this system; more than 25 Peasant Associations of rural farming community administered under adjacent Woredas were included under the Addis Ababa Administration under the Derg regime. After the overthrow of the Derg regime in 1991, the Transitional government of Ethiopia decided to limit its expansion to the place where it was before 1991 and to give due attention to its vertical growth. Vertical growth of Addis Ababa was believed to solve the problem. However, again it was believed that it poses problems since the majority of the Addis Ababa city dwellers are poor and cannot afford to construct high-rise dwellings (AACA, 2000: 10-12). 
On the other hand, Addis Ababa has attracted a large investment in the country. For example, in the first five-year strategic plan of the (FDRE) government (1997-2001) 54 percent of the total private investment applications submitted in the country requested to invest in and around Addis Ababa. This demand is met by converting large tracts of forest and farmland into urban use. The overall trend of Addis Ababa's population and area growth pattern indicates that it is the most accelerated growth rates in the world. This accelerated growth is also accommodated by the conversion of agricultural and forest land to urban settlement. Moreover, Addis Ababa has been encroaching more than 400 hectares of agricultural and forest land into urban administration for urban land use every year. As it has been tried to point out in the above statements, this has an adverse effect on the livelihood, socio-economic situations of peasants who used to live on those places. Because the growth of the city is at the expense of peasants livelihood, land possession and social security (AACA 1997:7).

Jimma is old aged town in the South Western Ethiopia with population number of near 150,000 according to the recent census of Ethiopia in 2007. The effect of horizontal urban expansion for variety of purposes on the livelihood strategy of households dwelling around the periurban areas of Jimma town was rarely studied from sociological point of view. Out ward expansion of urban settlements and institutions are observed in all corners of Jimma. For example, Jimma Airport and other organizations were constructed on the farmlands previously used by farmers. This is not to denounce construction of the large scale development projects at the fringes of the cities and towns but in order to reduce the suffering of people who are displaced for that purpose. Therefore, this study focuses on the consequences of displacements for the sake of huge development projects on the livelihood of small scale farming households.

\section{Statement of the Problem}

"Cities, it is claimed, take up too much space, encroaching excessively on agricultural land. Aesthetic benefits from the presence of open space are lost, and an allegedly scarce resource, namely farmland, is depleted. Excessive urban expansion also means overly long commutes, which generate traffic congestion while contributing to air pollution. “(QI Lei and LU Bin, 2008:1).

Urban sprawl or horizontal expansion of cities and towns towards outskirts defined as a form of low density spatial development, always characterized by scattered and discontinuous leapfrog expansion or segregated urban land uses. Recently, it has been evident that cities encroaching towards outskirts at the expense of farm lands and natural resources. The aesthetic benefits from open spaces, the livelihood of farming 
community at the peri-urban area are being increasingly replaced by urban settlements. This situation is highly evident in mostly around larger cities including developing countries. Thus, it is possible to argue that cities are becoming a zero-sum scenario since they are expanding at the expense of farm land and other natural resources which are fundamental for the existence of inhabitants particularly in urban centers where there is little farm land( QI Lei and LU Bin, 2008).

Urbanization in most countries has historically pushed all forms of agriculture out of the city and into rural areas, considering it too dirty for the glory of the city. Land use regulations today still follow that same path, despite prevailing evidence that producing food within cities today would solve many threatening problems. Governments today tend to systematically seek firms, residences, or commercial centers that will bring them the monetary return, using the rationale that the income generated for the city from this sort of land use will provide the money for the social services the government provides. This system, however, fails to take into account environmental and social sustainability, and equitable food security (Gittleman, 2009).

The Ethiopian urban centers are expanding in unexpected rate resulting to peasant displacement with concomitant loss of agricultural land and change of their livelihood. Generally, urban expansion is spontaneous phenomenon that leads to spontaneous growth by displacing rural farming community. It has been pointed out that even planned displacement has its own negative effect on the livelihood and the post displacement life of the affected community when the government uproots people for the purpose of expansion, they are also decreasing the amount of land available for cultivation. According to the experience of city expansion in Ethiopia, agricultural communities are relocated and left with little compensation, with no training for other skills to rely upon in a city with already very few employment opportunities. The government expects them to use the small compensation money for investments in new livelihoods and homes, particularly in their new condominium project, but this does not often happen (Gittleman, 2009; Tegegne, 1999:69; Firew, 2010:1-2 and Eyasu, 2007).

Firew (2010:1-2) has tried to point out that horizontal urban expansion or urban sprawl inevitably results to displacement of peri-urban farmers. The displacement schemes are always followed with compensation. However, in developing countries like Ethiopia where land ownership belongs to public, the amount of compensation paid to displaced peasants depends on government's good will. If the payment is insignificant, it directly leads to insecurity of life of evicted communities. For example, the studies conducted in the sub-urban community of the Hawassa city indicate that the surrounding peri-urban community is prone to the horizontal 
expansion of the city and faced livelihood adjustment problem beyond the compensation. Thus, the expansion of the urban settlement to fringes result in a significant change in the way of life, production, and social structure. In some cases the "win-loss scenario prevails during horizontal urban expansion"i.e. the firms become profitable at the expense of farmers. Therefore, it is important to identify the specific influence the horizontal urban expansion has on the livelihood of the peri-urban community after their relocation.

In some regions in Ethiopia, the situation is worsened by the absence of land expropriation and compensation directives. This kind of situation happened in Hawassa sub-urban area. Although Proclamation No455 (2005) on land expropriation and compensation to its effect provides direction on how the private holdings are to be expropriated and what and how the compensation is to be executed at the Federal level, in the Hawassa City, however, there is no such directives and legal provisions in this regards. Because of that, the peri-urban agricultural community has been affected adversely by the decisions of municipality in Hawassa (Firew, 2010).

Under such circumstances, the existence of good strategic/integrated planning is essential. According to the UN-HABITAT (1996:26), the strategic planning is the key instrument to safeguard the adversary effects of urbanization and to gain most out of it. And this, the strategic plan, needs to be participatory in such a way to integrate urban development to achieve growth management and responsive remedial actions at both the city and Sub-urban level. Similarly, the peri-urban agricultural community of Jimma faces the same situation although there are some guides to evict the land (Firew, 2010).

It has been mentioned that, the urban land lease policy is not very friendly to rural households in general and the poor land holders in particular. Because, the policy was criticized as it has not taken into account the lives of rural households living in the vicinity of towns and cities. As a result, the implementation of the policy has been marginalizing the rural settled farming communities. The non-farm based economic sector was not developed to absorb those displaced from farming, most of which are unskilled laborers. This indicates that the non-integrative type of urban expansion or development-induced displacement has negative effects on those of marginalized rural communities and forces them to live in poverty, food insecurity and hopelessness. This is because forced displacement can destroy community's previous means of livelihood and introduce new way of life that in most cases is less supportive than the previous (Tegegne 2000; Yeraswork and Fantu, 2003).

According to Feyera (2005) although Addis Ababa City Administration has put in place some benefit package, little is known how 
displacement and relocation is mediated, the livelihood of the displaced is protected in Jimma town and other towns in regional states of the country. The rural farming community has little knowledge and know-how to adapt to the situation of urban life as most of them are unskilled to compete for urban job opportunity. Especially, there is a common concern that the livelihood strategies of farming community can be exposed to economic and social problems that lead them to impoverishment.

Gittleman (2009); Feyera (2005); Frew (2000); Carter (1995) and others had tried to study that whether the displaced people find new homes and what is happening to them. However, the situation of displacement, relocation and its impact on the life making of the ex-farmers around regional towns were less studied. Therefore, this study will focus mainly on the eviction of land of farmers, livelihood of ex-farmers relocated to urban area from sub-rural area, their attitude towards outward growth of city to hinterlands and the stance of government towards urban sprawl and its effect on the surrounding farmers. The multi-faceted effect of the processes of urban expansion on the surrounding farming community needs to be clearly known in order to reduce the negative impacts. Therefore; it is essential to understand the situation for the improvement of livelihood maladjustment of dislocated farmers.

\section{Objectives of the Study}

General Objective

The general objective of the study is to investigate the situation of urban sprawl and the livelihood adjustment problems of peasants at the outskirts Jimma city.

\section{Specific Objectives of the Study}

- To examine the livelihood of ex-farmers in the relocated neighborhood

- $\quad$ To examine the benefit packages offered to ex-farmers

- To compare and contrast the life of the displaced households in the previous area and the current area.

- $\quad$ To examine the coping strategies of ex-farmers

\section{The Research Methods}

Since the study focuses on households displaced from the specific area and their number is few, Qualitative research method was used in order to examine deeply. Qualitative techniques are very important to study the living condition of displaced households. The qualitative data collection instruments such as; interviews, observations, case studies and focus group discussions were employed according guide lines and checklists prepared. 


\section{The sources of data}

Both secondary and primary data were used in this study. The primary data sources include; key-informant interviews with ex-farmers, focus group discussions with ex-farmers. Whereas the secondary sources were research works, journals, articles and books related to the issue at hand.

\section{Sampling design or Selection of the informants}

The subjects of our study were purposively selected. Key informants were selected from Hirmata Mercato kebele particularly from people who came from Derba. Readily available amount of ex-farmers were interviewed via qualitative data collection instruments in Hirmata Mercato Kebele. Seventeen (17) in-depth interviews with relocated household members were made who displaced from Derba. Three case studies were also conducted. One focus group discussions was undertaken in the area with the ex-farmers. In addition to that the living condition of 10 ex-farmers was observed by the researchers based on the observation checklists.

\section{Data presentation and Analysis}

Qualitative data collected via various types of qualitative data collection instruments were analyzed by using the thematic approach. The objectives set apart at the beginning are divided into various themes. Then were selected and the data under each themes presented, interpreted and analyzed thoroughly.

\section{Scope and Area of the study}

The study area is situated in the South eastern part of Jimma town in the sub city of Hirmata Mercato. Jimma is the oldest town in the south western part of the country. The city acts as the center for education, transportation, trade and cultural enhancement for the entire south western region of the country. Though the majority of the surrounding community of Jimma town is agrarian, because of the emergence of several service organizations such as air ports, educational institutions, etc., the city is also expanding into nearby agricultural land. Due to these developments, displacement and relocation is inevitable. Thus, this study is focused on examining the influence of urban expansion on the living of ex-farmers who become relocated from Derba area to the outskirts of Hirmata Mercato.

In this study, the livelihood adjustment problem of ex-farming households, to examine the livelihood of ex-farmers in the relocated neighborhood urban area, to examine the benefit packages offered to exfarmers, to examine the coping strategies of ex-farmers. Therefore, the subjects of the study were the ex-farmers who were used to live in Derba and relocated to the town of Jimma Particularly and living in Hirmata Mercato. 


\section{Definition of Terms}

\section{Ex-Farmers}

It refers to households who were previously engaged in agricultural activities but later on engaged in non-agricultural activities after relocated to urban settlements.

\section{Derba}

Refers to the place where the households who were relocated to Hirmata Mercato inhabited previously.

Peri-urban community refers to those of households who dwell at the outskirts of cities and depend on farming as their main livelihood strategy.

\section{Urban sprawl}

It refers to the horizontal encroachment of towns or cities towards their fringes or outskirts at the expense of livelihood of peri-urban community.

Pachchasa: a plot of the farming land which is equivalent to one and half hectare.

Leapfrog expansion of urban centers: a type of sprawl which occurs in advanced nations larger cities and characterized by jumping over the available open spaces or farmlands.

\section{Livelihood}

According to Chambers and Conway (1992), as cited in Sheilla et al.2001, livelihoods compromise(s) the capabilities, assets (including both material and social resources) and activities required for a means of living. A livelihood is sustainable when it can cope with and recover from stresses and shocks and manage to enhance its capabilities and assets both now and in the future, while not undermining the natural resource base.

Hirmata Mercato kebele: refers to the place where 45 households displaced from Derba relocated. It is one of the sub-cities of Jimma Town in the south western Ethiopia.

\section{Results and Analysis}

In this part, data collected through various data collection instruments such as in-depth interview with ex-farmers, focus group discussion with some the displaced people, in-depth interview with selected individuals from local urban governments were analyzed qualitatively. According to the themes set apart below in this chapter, analysis of the data was made. Thus, the socio-economic backgrounds of the ex-farmers, the extent of 
participation of ex-farmers in the decision of urban expansion program, the benefit of urban expansion for farming community at the edges of the city, impacts of urban expansion on the livelihood of peri-urban agricultural community, the coping mechanisms of ex-farmers, compensation packages for the displaced, the essence of training and orientation before relocation of for ex-farmers is presented, interpreted and analyzed thoroughly.

\section{Socio-Demographic Background of the Informants}

In this part, the general socio-economic status of the informants is addressed. The educational status, income level they earn, sex, age, ethnicity of the informants is presented, interpreted and analyzed. The data was collected through qualitative ways and the analyzing also follows the same way.

All the informants are currently living in Jimma town, Hirmata Mercato kebele. All of them came from 'Derba peri-urban neighborhood'. Derba was the area inhabited by the farming households before their relocation to the outskirts of the Hirmata Mercato sub-city. The total households who relocated this area were 45. For the purpose of convenience the needed qualitative data was collected from 17 households.

The members of the households are dominated by youths with age ranging from childhood to adults. The heads of the household's age ranges from 30-50. In majority of the households, the composition of family is dominated by children and teenagers below 18 years old. This indicates the existence of large dependent segment of dwellers in that neighborhood. Heads of the households are the sole providers for the day to day lives of the household members.

Regarding the place of origin, as it has been mentioned in above statement, all of them are indigenous people living in the area for a prolonged time. Currently, the entire neighborhood was uprooted from Derba and settled in the Hirmata Mercato kebele. And hence, although they live in part of city, their life to some extent is similar to that of the rural one. Because, without mixing with other households, all the 45 households came to the area and live together. According to the results of the interview and the Focus group discussion, there is a good social solidarity among them compared to other urban dwellers who are lacking genuine bond and cohesion between them due to heterogeneity.

Generally, the informants educational status was not beyond the primary level and seldom, some are completed their high school education. However, some members of the household are the holders of diploma and degree. Low educational status and impoverished life are positively correlated most of the time. Most of them have no dependable income earning activity. They depend on petty trades, baking injera, being employed 
as domestic workers and daily laborers. They are engaged in informal sector economy. Because they could not get formal employment due to their low educational preparation.

Regarding the family size, almost all households have the average family size of 6-8. Apart from the heads of the households of the informants, the remaining members are dependents on few individuals in the family. This indicates that the low socio-economic status is the common feature of the households in the study area. The low socio-economic status has a negative impact on their life success. For example, due to their low educational status; though they have started some type of livelihood strategy as a coping strategy in new neighborhood, they are not informed and awared to mitigate the pitfalls associated with their life making.

Ethnically, all the dwellers in the kebele were Oromo and the followers of Islam religion. Since the area by itself found in Oromia regional state, the households are indigenous people in the area. The source of cohesion in the areas where these people dwell is the similarity in religion and ethnicity. There is no anonymity, superficiality and ephemerality in social relationship and interaction though they are living within the large town of Jimma in South Western in Ethiopia.

Therefore, in terms of religion, ethnicity, educational status, and other variables, these households have similarity and the homogeneity in many aspects served as the sources of social solidarity and cohesion. All households are manifesting lack of anonymity. They know each other including their background. And hence, this is also another source of strong social capital which emanates from the strong networking. They use this social capital for various purposes like getting credit and loan though they are not economically better off.

\section{Participation of the Peri-Urban Community on the Relocation Scheme}

In this part, data concerning the participation of farmers on their fate before their displacement were collected extensively. Some of the themes stressed in this sub part include; awareness of ex-farming community concerning the expansion; the way how they get awareness; the reaction of farmers when they asked to leave the indigenous residence, participation in decision making regarding displacement and relocation, benefits obtained due to participation in decision making, availability of victims representatives in decision making about the relocation; and their stance towards city encroachment towards outward by consuming more farm land from time to time.

Concerning the participation of ex-farming households in the plan of city's outward expansion, one of our key informants told that they have no accurate information regarding their displacement and relocation process. He 
argues in his own words that "if we had informed accurate information timely about our fate, we would have been prepared properly in order to face the potential challenges." Instead of informing accurate information, the local urban bodies asked as to leave immediately the area. Some of them felt sad when they are hastily ordered to evacuate from their long time strongholds. They were systematically neglected from the direct participation in the plan of town expansion and displacement. Though there are elected committees which represent the voices of ex-farmers, informants believe that they are influenced by the local urban bodies. The government bodies are almost exclusively involved in determining the amount of benefit packages to the community.

Concerning their stance on government town expansion policies and plans, informants do not oppose it in principle. However, they reflect that the displacement program should be conducted with proper conditions for the displaced people instead of marginalizing and neglecting the victims of the problem. one of our informant said that "what can we do if the city expands? The same thing is happening in another area also. But what concerns us is lack of genuine implementation of what is said and promised." They also stress that a number of urban basic services were promised to provide on the side of government when we came to this area. Now almost five years have been passed since then but no electricity, water supply, road facility, school for children at nearby neighborhoods.

\section{The benefit Packages related with urban expansion for victims}

In this sub theme, the qualitative data concerning the base of livelihood of the displaced people, the benefit packages, the reaction towards the kind and amount of compensation ; the existence of prior orientation; support from any institution, the services offered that was non-existent before were collected and analyzed thoroughly.

These households in Derba had an established life making strategy. Farming, cattle herding, fodder production, forestry, poultry keeping like hen and some sort of the crafts industry are some of the life making strategies the informants were engaged.

The main benefit packages promised to be provided as compensation for the displaced include the money compensation before they leave their indigenous farming neighborhood. Money compensation and a plot of land for housing were given as compensations for the displaced. Informants are neither satisfied nor dissatisfied by the compensation according to the interview. Though they have no that much complain on compensation, they are not happy with the payment process because of the delliance and intermittent payment. The Informants stressed that after taking the phase one payment, a number of months have passed till they pay the next one. Some 
households could not use properly the compensation money. The advisory support for the displaced was not given according to the informants. They argue that since they are socio-economically take low status, it would have been better if they have got advice, orientation, training particularly how to lead life in new neighborhood. Lack of acquaintanceship with urban life, they face the socialization problem to accommodate themselves with the mainstream urban social interaction. It was obvious that they stayed for a prolonged time around the peri-urban area, however, the farming communities at this area most of the time lead rural type of life. As a result, they become maladjusted for more than two or three years in their new neighborhood. This is a great loss because these group of households have no experience of leading life in urban settlements. They lived for a prolonged time as farmers in peri-urban areas. One of our informants known as Awol replied in his own words as the following;

\section{Case 1: Awol Abagojam (a pseudo name)}

"I don't think that it is something very important especially people like us. Personally, I prefer personally living in the previous area known as Derba. Actually, as far as there is no equitable compensation for our land, forests, its significance is negligible. Five years have gone since we came to this resettlement area from 'Derba', but the promised services were not materialized still now. Previously, in Derba, women were engaged in income generating activities to mention few; we have been selling forest products like fire wood, clay-works.i.e., pottery, dung collecting, however, this days none of them exist in this place and we only wait for the hands of our husband.

Concerning the compensation, it has been entirely unfair. This is because the amount that was given for us as compensation was 12,000 ETB, however, the property that we left there in 'Dereba' was as many fold as the provided (paid) compensation by the municipality. The municipality does not gave us exactly the calculated amount of money(as estimated by engineers and others-let alone the amount that we actually deserve, we even cannot get the estimated amount-that means within the process of estimating our properties, even there were problems like jumping deliberately some properties like 'eucalyptus' and other trees.

What matters most is, in her own word, "we have not been able of covering the cost of constructing our home because as you can ask the municipality, it is 12,000 birr that was paid for as compensation which cannot build toilet, let alone house". She added," to cope with shocks or challenges pushed onto us by the municipality, we sold, like many of our neighbours,half of the land,i.e. $250 \mathrm{~m}$ sqare so as to get money and to finish the house construction" 
Concerning urban related infra-structure, though the place is called urban when compared to their previous possessions in Derba, the place itself has no access to basic urban services like electric city, water supply, road, etc according to the informants.

\section{Case 2; Mohammed Abagero Ababiya (a pseudo name)}

The urban expansion is the factor that displaced us from our settlement area on which we inhabited since the 1950s.It harmed us because we left our prestige and opportunity of better survival there in Derba what we have possessed here in this kebele is a single house with a single serviceshelter only.

\section{Impacts of urban expansion on the livelihood of peri-urban agricultural community}

In this sub-theme, data concerning the influences of urban expansion on the living of peri-urban agricultural community and their coping mechanisms, total income they get before displacement, total asset possession of the informants, social capital, coping mechanisms were discussed thoroughly.

Concerning the effects of the urban expansion on the outlook of farmers before its actual implementation of the relocation program, some informants stressed that they have felt frustration because they have been forced to leave their stronghold without getting prepared for the total dislocation. As a consequence of that, they sold their assets in cheap price in order to be relocated hastily to the new area as of the order of local urban government. Relatively speaking, the life making strategy of farmers in the previous and new areas, they prefer their living in the previous neighborhood and they consider it as the most dependable. Because, they used to sell the fruits, dairy products, pottery products and other agricultural products. The outcomes of the sold items made them capable of lead secured livelihood strategy. However, in the new area, all this opportunities of livelihood enhancement are jeopardized since it is impossible to practice it in urban settlement.

When they are asked concerning the amount of earning annually they get, they claim that their previous earning from their livelihood was better and more secured than the outcome of livelihood currently they are engaged in. For example, one informant said that he gets annual earnings of 50,00060,000 birr. He added that as even there are other benefits in kind that are not included in the monetary calculation. However, the amount of earning he gets after the relocation is drastically reduced. Because, as it was mentioned in above, a variety of opportunities were missed in the new location. They had more diversification opportunities of living. In addition to that, they have 
missed the opportunity to raring of various types of live stocks, cultivating of fruits and raising forests in new area. After relocation to the new area from the "Derba" they earn as less as 6000-7000 birr per annum apart from their house and plot of land. Concerning the social capital of the displaced people, some of the informants replied that there is no significant difference between the social capital in previous area and new area. Since all the 45 households are relocated to the same area from the original place known as "Derba", their social relationship among the neighborhoods remain the same. However, there is a slight deterioration of the network in the new area. All of the members of the household are preoccupied with undertaking their livelihood. Unlike the previous time, household members are engaged in a variety of survival strategies compared to the previous one where almost everybody engaged in similar type of livelihood strategy. Regarding the difference of earning between the previous and current life making strategy, Semira Abdullah clarified as follows;

\section{Case 3; Semira Abdella (a pseudo name)}

"Since our source of income was generated from diverse sources (milking, renting, selling the firewood, pottery e.t.c) I do not know the exact figure (estimated 2000 birr/month, i.e. .24, 000 birr). And unlike the previous time, I become idle in this new urban setting (no opportunity to get income by selling products of pottery), the only source of income for our family is my husband's wage from daily laboring which is not regular. There is also lack of integration to the new life style in urban area. Through this kind of activities 30 or 40 birr can be earned."

\section{The coping mechanisms of ex-farmers}

In this sub-theme a varieties of the coping mechanisms employed by displaced people in new area will be discussed. Some of the coping mechanisms used by the informants include agricultural (urban farming like selling milk, egg, etc, though diminishing from time to time due to lack of support from concerned bodies) and non-agricultural activities like serving in some ones house or domestic service for women, daily laboring for the men in the city.

They express their unhappiness in new environment like this; "why the government resettle us in arable and fertile land since we have faced many sided problems? If there is land for agriculture-we can cope". They also do not hide the absence of the genuine representation of their concern during the program implementation. Actually, the committees did not been selected by the ex-farming communities, but by the initiation of themselves based on the available social network. Majority of the informants are not 
happy with the performance of committee members because they are assumed to have a pro-government attitude in the process of compensation payment and relocation process. And hence, the committees were not pro-the victims of the program according to the focus group discussion with informants. What would be better was if there had been fair property registration, calculation of all properties without partiality.

The displaced households engaged in productive activities after the relocation. Some of them engaged in agricultural activities like selling of buds, flower,) and others especially females engaged in baking injera, domestic service, street vending at mercato, and handcrafting. Although they have jobs currently they told me that it was very difficult to get job in the new neighborhood compared to their relatively secured living condition in Derba. Because, they did not get training concerning how to lead life in the new neighborhood. Again lack of money handling skill also affected their success in living condition in the new area. The compensation was also given at different time but not at one point in time. This has also its own effect on the relative deterioration of the stability of life in the new neighborhood.

\section{Case 4}

Regarding the coping with the difficult situation in new pace, one key informant explains in his own words," As I have told you, we have resettled here in Hirmata kebele from Derba exactly 5 year ago. By the time when we were living at that place, the government bodies came and told us in a meeting held in one kebele hall-that we are going to be displaced but with no time specified for the actual implementation. We also have been informed about the purpose-as they told us we were to be evicted for the expansion of'Airport'. As a compensation for our assets, a number of things were promised but only some of them are materialized. As a result, we face difficulty in leading our life normally when I compare it with the previous one. Previously, we have been supporting ourselves using coffee, avocado, forest products, etc, however, the hasty dislocation has not allowed us to get ready for the upcoming urban way of life. Hence, we came here with no prior information and readiness. Actually, there are some activities we are taking part to overcome the shocks and the vulnerabilities. As mentioned above, daily laboring, domestic service, baking injera, selling seedlings, etc are some of the coping mechanisms to be resilient to the vulnerabilities in the new area. Despite of that, living in urban area poses new challenge which was unanticipated. For example, we have to improve our housing physical structure which requires a strong financial asset. With this condition, it is unthinkable for us to do it. 
Moreover, they cannot keep their children in home out of school as an urban dweller.

\section{Compensation for the displaced:}

In this part, the nature of compensation offered for the displaced people from Derba will be addressed. Although there was no full participation of the subjects of the issue, compensation was given for all displaced households. Some of the informants complain that the determination of price for the properties like land, forests are not clearly stated. They also claim that there is a discrepancy between the promised compensation before their displacement and actual compensation after the displacement.

The process of calculating lestimating the amount of money to be paid per household had partly contributed for the declining social relationship between members even leading to animosity between us. Some of our neighbors have got 500,000 and some are paid 300,000 while others got 12, 000, 9000 birr. This situation contributed for the declining unity among people of the same background. Households who got lower compensation have not been felt sad.

The compensation from the insiders point of view is totally unfair, but the government said that it is enough and the difference between the amount estimated (e.g. 279,000) and the amount paid in cash (for example 180,000) is the total deduction for tax.

As it was pointed out in above, money and a plot of land to housing are one of the main compensations. Money compensation is criticized for its lack of fairness in payment. The price for items were determined by the representatives and the engineers. The impartiality of the representatives of the Derba is under complain around some of the members of relocated people. They claim that the representatives were pro-urban government during the determination of items of the farming households.

According to some informants, the compensation scheme should be attractive instead of frustrating. If it had been attractive and fair, there would had been no complain among the relocated people. Some people also argue that since the socio-economic status of people around the peri-urban area is low in terms of education, income, etc, they have little knowledge to handle the compensated money and cope up with the new situation in new areas. Moreover, on the behalf of the local urban government, there was no arrangement for training on the new situations that people will face. From the field observation, we have seen that some among the relocated people practice new type of livelihood based on their own knowledge without training. 


\section{Comparing the past and present situation of the Households:}

In this sub section, comparison of the life of households in Derba and Hirmata mercato will be depicted. In the process of comparison, the livelihood source, the type of social capital or assets, outcomes of their life making, acces to social services will be taken in to consideration.

Regarding the livelihood source, previously, there were agricultural products, forest products, milk and milk products, poultry and others that support their livelihood (for consumption and sale). Although they were not produce surplus, they led stable life since they have diversified source of income. They sell products of handcraft like pottery, grasses, trees for fuel wood and construction. At the times of shock, they can depend on either one of the aforementioned sources. They argue that the outcome of previous livelihood strategies were more dependable and enhancing their life in many aspects. They used to finance the needs and wants of their family adequately but now, although they are engaged in some sort of livelihood, they are easily affected by inflation of the prices of goods and services.

Concerning the social capital, social networking within themselves remain the same even in the Hirmata Mercato area. The difference comes when we refer to the interrelation of these households and other dwellers outside of them. They have little acquaintanceship with people outside them. Thus, nevertheless they are cohesively within themselves i.e. intra-social networking, they lack inter-social networking or bonding.

Regarding the access to basic social services, they complain that in terms of access, there is no change. This is because, the promises were not implemented. Some of them argue that they were more accessible to schools, market centers, and health stations when they were in Derba area. Despite of owning houses in town, some of them show preference to the previous way of life in Derba. This may be because of unimplemented promises and lack of support from the government side. In general, while some of these households consider the current way of life as in secured and vulnerable to various shocks compared to the life in Derba, which was romanticized as "secured, stable", there are also others who lead a progressing life and happy with the current way of life depending on the educational status of the household members.

\section{The Displacement and the Stance of Local Urban Government and Displacement}

In this section, the stance of local urban authorities will be addressed or analyzed in light of displaced people point of view. The stance of some experts from urban government will also be analyzed in this section.

Some of the ex-farming peri-urban community who live now in Hirmata Mercato kebele say that, "the base of our livelihood is not taken in 
to consideration when they relocate us.” Because, they are the community who depend on agriculture for their life making. When they become relocated to hirmata mercato, they faced difficult to re-establish their livelihood base. And it was difficult also to form a livelihood similar with previous one. Because of the basic difference between rural context and urban context, this group of people faced hardship in coping and reestablishing their livelihood although they were compensated to some extent. They depend highly on the natural resource in the peri-urban environment previously, but now it is impossible to depend on the natural resource base in urban area.

One informant from the urban authorities said, "that the plan of government was not to make the life of people miserable but to faclilitate the development of the town.to enhance this process, the compensation was also given to the displaced but the problem is their inability to handle and manage what is given for them as a compensation. The government is also constrained by lack of enough budget to compensate each and every individual things around the displaced people."

Urban authorities believe that their life is better than the previous one, because in the newly relocated area, they could get a plot of land, water services, electricity and other services though some they are denied by the displaced people. They assert that though all the promises are not still implemented, turn by turn some they are being implemented. And to change their life sustainably, the urban administration is planning with the stake holders.

Moreover, when one displaced person the situation "Land that has been used for agriculture by most households was not considered in the compensation. Why? The response provided by the authorities was "land belongs to the public'. If the case is so, there should be uniformity, but we know that some of our neighbors have got paid for their one hectare of agricultural land. He also added that, "Unlike the previous time, these days we have become far from school-because previously we have been sending our children to school-in Hamle School-the nearest one. Now we are in Hirmata Mercato kebele, yet we are sending them (the children) to Hamle school-too far now than before. The land for school construction have been allowed but the municipality came and showed interest to give it to someone else, but we refused them and consult the zonal education bureau and they told us to stand a tapella bearing the name and date of establishment of the school solved".

\section{Livelihood adjustment problems faced by ex-farming communities}

Ex-peasant communties in their post displacement time face many livelihood adjustment difficulties. As it was mentioned above,due to the 
differnce of context in rural and urban area, lack of training and follow-up regarding how to lead life in urban area,less amount of compensation for their previous properties were pointed out as the main sources of livelihood adjustment among the relocated ex-peasants from Derba.

Particularly,too much reliance on cash economy creates life insecurity among these communities. They stressed that since the compensation was less and there was no training to handle money,the compensated money lasted for short duration with them. Then they faced lack money to finance their needs and wants.The main cause for this was lack of dependable livelihood strategy after displacement.Due to that,they depend on the portfolio of livelihood strategies through diversifying their income. But the problem is those all diversification strategies are done for the survival strategy. Moreover,they also lack strong social capital with other neighborhood members. Since it needs a prolonged time to develop trust in the neighborhood, they as a recent comer to this new area affected by it negatively. Thus, it was this situation that makes their life precarious in newly relocated areas.

Thus,difference of context, less amount of compensation, lack of training and follow-up in post displacement life,lack of strong social capital vertically with others together with their low socio-economic status resulted them in livelihood adjustment difficulty in new area.

\section{Conclusion}

In this study, horizontal urban expansion in relation to the displacement process and its effect on the livelihood strategy of ex-farmers or people who used to live in that area before their displacement. It has been pointed out in the introduction and statement of the problem part the issue at hand was to some extent studied by various researchers around Addis Ababa. However, studies like this are little in Jimma. Since Jimma is one of the largest urban center in south western part of the country and the town is also showing a rapid population growth recently according to the census report of 2007, studies like this is appealing. Because, there are horizontal expansions and displacements although they are at their slow level.

To study urban sprawl or horizontal expansion and livelihood adjustment problem faced by ex-farming community, we have collected data qualitatively by employing in-depth interview with our key informants and other displaced people in the Derba area. In addition to the in-depth interview of key informants, focus group discussion was also conducted with some of the displaced people in new area of relocation. Together with other qualitative data collection instruments, observation based on the checklists was also conduced regarding their housing condition, what they do in the new area of relocation. 
Data collected via qualitative data methods analyzed qualitatively. Thematic analyzing of the qualitative data was used. Themes were selected based on the interview guide which were employed to get information from the interviewee.

Thus, by employing the aforementioned data collection instruments, information on the extent of out ward expansion of Jimma town, examining the livelihood of ex-farmers in the relocated neighborhood, examining the benefit packages offered to ex-farmers, examining the coping strategies of ex-farmers in the new area.

In light of the above objectives and methods, data was collected from the ex-derba dwellers and some assertions were made accordingly. The socio-economic background of the informants can be considered as poor. Because, the educational status of informants is not more than grade 4 and 5 although 2 exceptional informants with diploma and university degree. In their new neighborhood, they lack also basic urban services like potable water supply, electricity, standardized road facilities, schools, and health stations. In terms of this services, it is possible to say that the new neighborhood is neglected by the urban authorities except the hopes and future plans.

The level of participation was not significant and pleases the members of the Derba community. The peri-urban community or ex-farmers were not actively participated on the scheme of displacement. Their complain in the process of compensation payment, price determination, place selection, announcement before dislocation can be considered as one indicator lack of genuine discussion and representation in the process of displacement. There is also livelihood adjustment difficulties faced by these community members and it needs the intervention of concerned stake holders to mitigate the precarious situation they face in the new area.

\section{Acknowledgements}

First and foremost, we would like to thank Jimma University for funding this research project. Next, we would also like to thank Ato Shafi and Gali from Jimma Town Administration for their cooperation by showing the neighborhoods where the displaced households settled. Lastly, Tegen Dereje who has helped us in collecting data for this project from field should be appreciated.

\section{References:}

AACA, (1997). The First Five Years (1997-2001) Development Plan. Addis Ababa: Addis Ababa City Administration.

AACA, (2000). The Second Five Years (2000-2004) Development Plan. Addis Ababa: Addis Ababa City Administration. 
Firew Bekele.2006.The Impact of Horizontal Urban Expansion on SubUrban Agricultural Community Livelihood: The Case of Tabor Sub-City, Hawassa city, SNNPRS, Ethiopia .MA Thesis unpublished; Addis Ababa University

Bekure Woledesemait (1999). 'For a men urbanized Ethiopia', in Beyene Doilicho, Mekete Belachew and Tegegne G. Egziabher (eds.), Migration and Urbanization in Ethiopia: Proceedings of the Second Annual Conference. Addis Ababa: Association of Ethiopian Geographers. Yeraswork Admassie and Fantu Guta (2003). Spatial Population Balance and Rural Liability in Ethiopia: Research Report on the Role of Agriculture made for FAO and Ethiopian economic Association. Addis Ababa.

Shalaby, A. \& Gad, A. .N.d. urban Sprawl Impact Assessment on the Fertile Agricultural Land of Egypt Using Remote Sensing and Digital Soil Database, Case study: Qalubiya Governorate. National Authority for Remote Sensing and Spatial national Authority for Remote Sensing and Space Sciences, Egypt 